\title{
Benefícios da intervenção fonoaudiológica no transtorno do espectro autista: Revisão
}

\section{de literatura}

\author{
Benefits of speech therapy intervention in autism spectrum disorder: Literature review \\ Beneficios de la intervención de logopedia en el trastorno del espectro autista: Revisión de la
} literatura

Recebido: 27/04/2021 | Revisado: 05/05/2021 | Aceito: 21/05/2021 | Publicado: 08/06/2021

\author{
Jessé Lincoln Oliveira Araújo \\ ORCID: https://orcid.org/0000-0002-5134-081X \\ Faculdade de Ensino Superior do Piauí, Brasil \\ E-mail:jesselincolnn@gmail.com \\ Cláudia Catão de Aguiar Sousa \\ ORCID: https://orcid.org/0000-0002-6193-7484 \\ Faculdade de Ensino Superior do Piauí, Brasil \\ E-mail:klaudyakatao@hotmail.com \\ Ruth Raquel Soares de Farias \\ ORCID: https://orcid.org/0000-0002-0988-0900 \\ Faculdade do Ensino Superior do Piauí, Brasil \\ E-mail: ruthraquelsf@gmail.com
}

\begin{abstract}
Resumo
O Transtorno do Espectro Autista (TEA) pode sem compreendido com uma espécie de desordem referente ao neurodesenvolvimento, caracterizada pela alteração nos aspectos sociocomunicativos e nos comportamento com limitações nos interesses. Salienta-se que os problemas na linguagem apresentam como principais características dificuldades em aspectos semânticos, pragmáticos, sintático, paralinguísticos, e fonológico. O objetivo principal da presente pesquisa consiste em analisar a importância das intervenções fonoaudiológicas em crianças autistas. Dentre os objetivos específicos ressaltam-se: Verificar quais as dificuldades existentes no autista no processo de aquisição da linguagem; Apresentar modelos e/ou estratégias de intervenção fonoaudiológa junto ao autismo; Descrever os a importância dos programas terapêuticos de intervenção fonoaudiológicas no desenvolvimento da comunicação dos autistas. Para a fundamentação da pesquisa houve a necessidade de uma revisão bibliográfica do tipo integrativa, anlisando diversas fontes, presentes em artigos científicos, disponíveis nas bases de dados da Scielo, Pubmed, Google Acadêmico e Capes. Foi evidenciado por meio da pesquisa que são eficazes no desenvolvimento da criança autista possibilitando um maior benefício no desenvolvimento comunicativos desses seres humanos.
\end{abstract}

Palavras-chave: Autismo; Fonoaudiologia; Fonoterapia.

\begin{abstract}
Autistic Spectrum Disorder (ASD) can be understood with a kind of disorder related to neurodevelopment, characterized by changes in socio-communicative aspects and in behaviors with limited interests. It should be noted that the main language problems present difficulties in semantic, pragmatic, syntactic, paralinguistic, and phonological aspects. The main objective of this research is to analyze the importance of speech therapy interventions in autistic children. Among the specific objectives, the following stand out: Check which difficulties exist in the autistic person in the process of language acquisition; Present speech therapy models and / or strategies with autism; Describe the importance of speech therapy therapeutic intervention programs in the development of autistic communication. To support the research, there was a need for an integrative bibliographic review, analyzing different sources, present in scientific articles, available in the databases of Scielo, Pubmed, Google Acadêmico and Capes. It was evidenced through research that they are effective in the development of the autistic child, enabling a greater benefit in the communicative development of these human beings.
\end{abstract}

Keywords: Autism; Speech therapy; Speech.

\section{Resumen}

El Trastorno del Espectro Autista (TEA) puede entenderse con un tipo de trastorno relacionado con el neurodesarrollo, caracterizado por cambios en los aspectos sociocomunicativos y en las conductas con intereses limitados. Cabe señalar que los principales problemas del lenguaje presentan dificultades en aspectos semánticos, 
pragmáticos, sintácticos, paralingüísticos y fonológicos. El principal objetivo de esta investigación es analizar la importancia de las intervenciones de logopedia en niños autistas. Entre los objetivos específicos, se destacan los siguientes: Comprobar qué dificultades existen en el autista en el proceso de adquisición del lenguaje; Presentar modelos y / o estrategias de terapia del habla con autismo; Describir la importancia de los programas de intervención terapéutica de logopedia en el desarrollo de la comunicación autista. Para sustentar la investigación, fue necesaria una revisión bibliográfica integradora, analizando varias fuentes, presentes en artículos científicos, disponibles en las bases de datos de Scielo, Pubmed, Google Acadêmico y Capes. Se evidenció a través de investigaciones que son efectivos en el desarrollo del niño autista, posibilitando un mayor beneficio en el desarrollo comunicativo de estos seres humanos.

Palabras Clave: Autismo; Terapia del lenguaje; Lenguaje.

\section{Introdução}

O autismo pode ser considerado com um transtorno do desenvolvimento infantil, apresentando um diagnóstico bastante complexo, com a sua identificação de forma inicial realizada pela observação do comportamento verbal e do comportamento não verbal, conforme os critérios definidos no DSM V (Manual de Diagnóstico e Estatística dos Transtornos Mentais, American Psychiatric Association), existindo, desse modo, a necessidade de um tratamento sistemático, tanto em curto como em longo prazo (Kasari, 2016).

De acordo com o DSM -V o Transtorno do Espectro Autista (TEA) é caracterizado como uma desordem do neurodesenvolvimento, marcada por alterações na díade: sociocomunicativo e comportamental. Além disso, engloba déficits no que se relaciona com o funcionamento do cérebro da criança em desenvolvimento, ocasionando como as principais consequências o atraso na fala, na aprendizagem e, também, na obtenção dos gestos motores (Soares et al., 2015).

Conforme evidenciado são diversos os problemas apresentados por crianças autistas, as quais necessitam da intervenção de profissionais da saúde, como, por exemplo, os profissionais da fonoaudiologia, em prol de um melhor desenvolvimento da criança, especialmente, em assuntos pertinentes a fala, dentre outros, diretamente relacionados com o desenvolvimento da linguagem.

O objetivo geral da pesquisa consiste em analisar os principais benefícios da intervenção da fonoaudiologia em crianças com o transtorno do espectro autista; dentre os objetivos específicos: Verificar as principais dificuldades existentes no autismo no processo de aquisição da linguagem; descrever modelos e/ou estratégias de intervenção fonoaudiológica junto ao autismo; Demonstrar a importância dos programas terapêuticos de intervenção fonoaudiológicas no desenvolvimento da comunicação dos autistas.

O autismo tem sido tema de importantes debates, tanto em âmbito nacional quanto global. Diversos autores, alguns pais e familiares, profissionais, acadêmicos, gestores, os próprios autistas e outros ativistas, têm promovido ampla discussão a partir de diferentes posições sobre os possíveis fatores etiológicos, a descrição nos gráficos do transtorno e as metodologias supostamente eficazes de tratamento, assim como a organização de políticas de cuidado e o arcabouço legal de garantia de direito (Oliveira, et al., 2016).

Tomando como foco tais premissas sobre os benefícios das intervenções fonoaudiológicas no processo de desenvolvimento da comunicação do autista apresenta-se a seguinte problematização: Até que ponto as intervenções fonoaudiológicas contribuem para o desenvolvimento da comunicação do indivíduo com transtorno do espectro autista (TEA)?

Justifica-se a escolha do presente tema da intervenção da fonoaudiologia em crianças com o Transtorno do Espectro Autista devido a indispensabilidade da atuação multidisciplinar com a finalidade do desenvolvimento desses seres humanos, em especial, o papel do fonoaudiólogo, profissional que possui o papel de intervenção direta no que se relaciona com as habilidades de comunicação e de socialização, com o objetivo de proporcionar para as crianças autistas uma maior autonomia e o uso da linguagem funcionalmente em prol da interação com o meio no qual se encontra inserida (Isaías, 2019). 


\section{Referencial Teórico}

\subsection{O transtorno do espectro autista}

Em conformidade com dados provenientes da Organização Mundial de Saúde (OMS), aproximadamente, 70 milhões de pessoas no mundo são autistas, sendo uma maior incidência em pessoas do sexo masculino, sendo que suas causas ainda não estão determinadas. No entanto, pesquisas demonstram que vários fatores tornam uma criança mais propensa ao Transtorno do Espectro Autista, ressaltando fatores genéticos e fatores ambientais.

O Transtorno do Espectro Autista (TEA) é definido como um distúrbio de desenvolvimento neurológico apresentado desde a infância, comprometimentos de ordem sócio comunicativa e comportamentais. Devido sua complexidade, para que os pacientes sejam avaliados e enquadrados dentro do espectro autista é necessário que preencham os critérios do diagnóstico sugeridos pelo Manual de Diagnósticos e Estatísticas dos Transtornos Mentais - DSM. (APA,2014).

O autismo é uma condição de saúde pautada por um déficit relacionado com a comunicação social e comportamento, não sendo apenas um mas vários subtipos desse transtorno. É tão abrangente que se utiliza o termo "espectro", devido aos vários níveis de suporte que necessitam, existindo desde pessoas com outras enfermidades e condições associadas (coocorrências), como também deficiência intelectual e epilepsia, até pessoas independentes, com uma vida comum, e algumas, mesmo, nem sabem que são autistas, pois nunca tiveram um diagnóstico preciso.

\subsection{Diagnóstico}

Ainda que o transtorno autista possa vir associado a diversos problemas neurológicos e/ou neuroquímicos, não existe ainda nenhum exame específico que possa detectar a sua origem. Os diagnósticos são formulados sempre a partir da observação de um conjunto de sintomas apresentados pela pessoa (Ischkanian, 2014).

Conforme a Associação Americana de Psiquiatria (APA) o diagnóstico é feito por meio da díade do TEA, ou seja, por (a) déficit na interação social e comunicação e (b) comportamentos e interesses restritos e repetitivos (APA, 2014). Assim de acordo com Araujo e Neto (2014, p. 70):

[...] os Transtornos Globais do Desenvolvimento (TGD), que incluíam o Autismo, Transtorno Desintegrativo da Infância e as Síndromes de Asperger e Rett foram absorvidos por um único diagnóstico, Transtornos do Espectro Autista. A mudança refletiu a visão científica de que aqueles transtornos são na verdade uma mesma condição com gradações em dois grupos de sintomas: déficit na comunicação e interação social; padrão de comportamentos, interesses e atividades restritos e repetitivos. Apesar da crítica de alguns clínicos que argumentam que existem diferenças significativas entre os transtornos, a APA entendeu que não há vantagens diagnósticas ou terapêuticas na divisão e observa que a dificuldade em subclassificar o transtorno poderia confundir o clínico dificultando um diagnóstico apropriado.

Considerando a citação apresentada, nas pontuações de Lord e Bishop (2014) o Transtorno do espectro autista (TEA) com o DSM V passou a incluir apenas duas características para seu diagnóstico: a comunicação social e os comportamentos. Isso por entender comunicação e interação social como indissociáveis, separadas anteriormente por meras questões didáticas.

Com relação ao aspecto comunicação conforme o Manual de orientação do Transtorno do espectro do Autismo (2019, p.4):

O comprometimento da linguagem pode ser verificado através de um discurso de mesma entonação, empobrecido na linguagem não-verbal e no entendimento da linguagem de sentido figurado[...] Alterações nos domínios da comunicação social e linguagem e comportamentos repetitivos entre 12 e 24 meses têm sido propostos como marcadores de identificação precoce para o autismo. 
Observa-se que o comprometimento da linguagem surge como uma das primeiras preocupações observadas no desenvolvimento das crianças atípicas, considerado um sinal clínico para o diagnóstico do TEA. Tendo o diagnóstico é relevante que se busque intervenções adequadas, realizadas por equipe interdisciplinar, visando através destas modalidades terapêuticas um desenvolvimento tanto no aspecto social e comunicativo evitando futuros danos (Manual De Orientação Do Transtorno Do Espectro Do Autismo,2018).

Embora as alterações de linguagem, para o diagnóstico do TEA não seja uma condição exclusiva, ela possui uma importância relevante na caracterização autismo, pois observa-se que a maioria dos autistas apresentam atrasos e desvios no desenvolvimento da mesma observando-se maior comprometimento no nível pragmático e nos aspectos não verbais (Oliveira, et al.,2018).

São diversas as características relacionadas com o Transtorno do Espectro Autista (TEA), ressaltando-se, principalmente: Dificuldade para a interação social, problemas com a linguagem, além de um comportamento caracterizado pela repetição e restrições.

Alguns sintomas como irritabilidade, agitação, autoagressividade, hiperatividade, impulsividade, desatenção, insônia e outros podem ser tratados com medicamentos, que devem ser prescritos por um médico.

\subsection{A intervenção Fonoaudiológica em Crianças autistas}

Com relação às intervenções realizadas por estes profissionais, Oliveira et al., (2018) considera que o ABA (Applied Behavior Analysis) e PECS (Picture Exchange Communication System) juntos contribuem para uma melhoria significativa da comunicação. O fonoaudiólogo irá trabalhar a estimulação das habilidades de comunicação verbal e não verbal, e eventuais distúrbios de aprendizagem.

Com base na apresentação clínica das crianças, os profissionais da fonoaudiologia passam a intervir em aspectos relacionados com o desenvolvimento da linguagem, pois esta é de suma importância para que ocorra uma adequada interação social, possibilitando, assim a promoção dos aspectos comunicativos de forma ampla e pautada na eficiência, contribuindo diretamente na habilitação e, consequentemente na redução dos déficits que a criança autista tende a apresentar na sua integração na sociedade. Sendo assim é de suma importância que o fonoaudiólogo sempre possua um olhar, tanto, individualizado, como um olhar clínico direcionado as principais necessidades dos indivíduos (Bagarollo e Panhoca, 2010; Saad e Goldfeld, 2009).

\section{Metodologia da Pesquisa}

No que se refere a metodologia a presente pesquisa caracteriza-se como uma revisão bibliográfica integrativa, por meio da análise de vários estudos na literatura internacional e nacional sobre a importância da intervenção fonoaudiológica no desenvolvimento de crianças autistas.

Para a fundamentação da pesquisa houve a realização de investigações de várias teorias bibliográficas presentes em diversas bases, ressaltando-se a Scielo, Pubmed e Capes.

Com o objetivo de lograr um maior êxito na busca das fontes de pesquisa houve a seleção dos seguintes descritores em saúde (decs), ressaltando-se: autismo, fonoaudiologia, fonoterapia.

Dentre os critérios de inclusão somente foram incluídos na pesquisa artigos que tratassem somente da intervenção da fonoaudiologia no transtorno do espectro autista, sendo excluídas as fontes que apresentavam a importância da fonoterapia em outros transtornos. 
O segundo critério de inclusão pautou-se no lapso temporal da elaboração dos artigos, sendo incluídos somente fontes cuja publicação tenha ocorrida entre os anos de 2015 a 2021, sendo excluídas fontes de pesquisa fora desse lapso temporal.

Após o critério de inclusão e de exclusão foram encontrados 28 artigos, no entanto somente 10 artigos estavam relacionados com a intervenção fonoaudiológica em crianças com transtorno do espectro autista, sendo 3 encontradas na base de dados da Pubmed, 5 na base de dados Scielo e 2 no portal de periódicos capes.

Os artigos que estão disponíveis em mais de uma base de dados foram contabilizados apenas uma vez (Figura 1).

Figura 1: Quantidade de artigos conforme a base de dados.

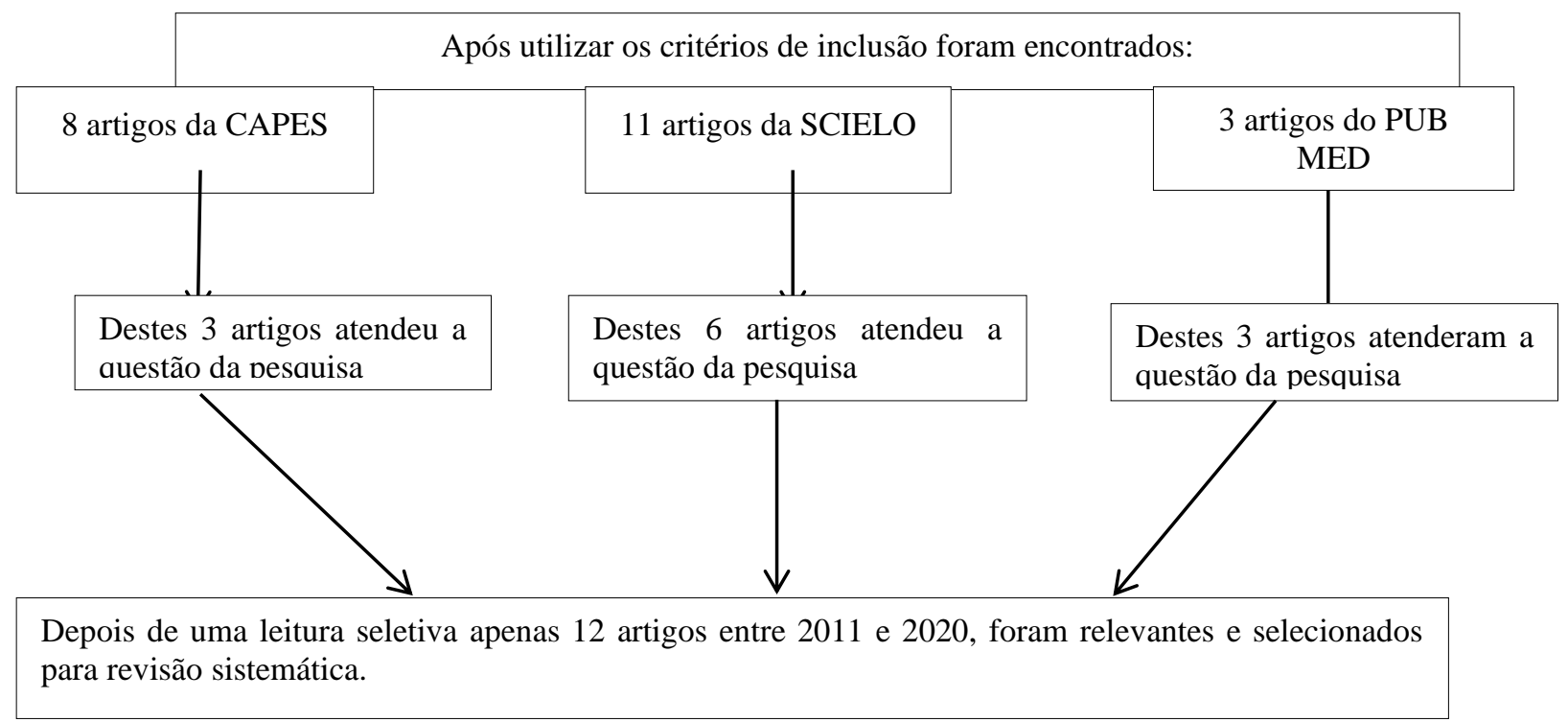

Fonte: Autores.

Posteriormente a seleção dos artigos que seriam utilizados na presente pesquisa houve a necessidade da elaboração de um quadro identificando os seus autores, a base de dados na qual está disponibilizado o artigo, a metodologia e os resultados presentes nas fontes consultadas.

\section{Resultados e Discussão}

Após análises de várias teorias, presentes, principalmente em artigos científicos, livros e consultas na rede mundial de computadores, analisando principalmente revistas científicas, referente às principais contribuição da fonoaudiologia para o desenvolvimento de crianças diagnosticadas com o espectro autista.

O quadro de número 1 demonstra de modo objetivo, conforme se evidenciou na pesquisa as principais contribuições da fonoaudiologia para crianças autistas. 
Quadro 1. Benefícios da fonoaudiologia para o desenvolvimento de crianças com transtorno do Espectro Autista

\begin{tabular}{|c|c|c|c|}
\hline Autor/Título & Base de dados & Amostras & Conclusão \\
\hline $\begin{array}{l}\text { Cardoso, C (2017) } \\
\text { Fonoaudiologia } \\
\text { autismo: resultado de } \\
\text { três diferentes modelos } \\
\text { de terapia de linguagem }\end{array}$ & Scielo & $\begin{array}{l}\text { Os sujeitos foram crianças e } \\
\text { adolescentes com diagnósticos } \\
\text { psiquiátricos incluídos no espectro } \\
\text { autístico em início de processos de } \\
\text { terapia fonoaudiológica. Os } \\
\text { participantes foram divididos em três } \\
\text { grupos de acordo com o desenho } \\
\text { terapêutico oferecido por um período de } \\
\text { seis meses. }\end{array}$ & $\begin{array}{l}\text { Não indicaram diferenças estatisticamente } \\
\text { significativas, embora observáveis. O grupo } \\
\text { com mais indicadores de progresso durante o } \\
\text { período específico de intervenção } \\
\text { diferenciada, foi o grupo A, em que os sujeitos } \\
\text { eram atendidos em duplas. O resultado não } \\
\text { previsto foi que não só em nenhum dos grupos } \\
\text { foi observada diminuição dos índices obtidos, } \\
\text { após um período de seis meses, como em } \\
\text { algumas situações o número de sujeitos com } \\
\text { progresso aumentou após esse período. }\end{array}$ \\
\hline $\begin{array}{l}\text { SANTOS, THF (2017) } \\
\text { Fatores intervenientes na } \\
\text { terapia fonoaudiológica } \\
\text { de crianças autistas }\end{array}$ & Scielo & $\begin{array}{l}\text { Crianças atendidas em sistema } \\
\text { ambulatorial, uma vez por semana, num } \\
\text { serviço especializado, por } \\
\text { fonoaudiólogas pós-graduandas na área } \\
\text { há aproximadamente seis meses antes } \\
\text { dos primeiros relatos apresentados. }\end{array}$ & $\begin{array}{l}\text { É interessante observar que todas as crianças } \\
\text { tiveram progressos importantes em suas } \\
\text { manifestações, como engajamento em } \\
\text { atividades de atenção compartilhada e jogo } \\
\text { simbólico e, aumenta significativamente a } \\
\text { proporção de comunicação interpessoal. }\end{array}$ \\
\hline SOUZA, APR (2018) & Scielo & $\begin{array}{l}\text { Foi realizada análise qualitativa da } \\
\text { interação dialógica, antes e após três } \\
\text { meses de terapia de linguagem de base } \\
\text { dialética, por meio de filmagem e } \\
\text { transcrição da interação linguística e } \\
\text { não-linguística em } 45 \text { minutos de } \\
\text { sessão, de três sujeitos do espectro } \\
\text { autístico entre seis e oito anos de idade. }\end{array}$ & $\begin{array}{l}\text { Os sujeitos ampliaram sua participação } \\
\text { dialógica em situações de interação verbal, } \\
\text { apresentando progressos no funcionamento da } \\
\text { linguagem. Desta forma, é possível afirmar a } \\
\text { eficácia e efetividade da abordagem na } \\
\text { terapêutica de linguagem em sujeitos do } \\
\text { espectro autístico, pois permite perceber o } \\
\text { avanço no funcionamento da linguagem. Os } \\
\text { movimentos terapêuticos consistem em } \\
\text { ancorar as enunciações dos sujeitos atribuindo } \\
\text { sentido e mantendo o tópico de discurso. }\end{array}$ \\
\hline $\begin{array}{l}\text { CASTRO, SJ (2015) } \\
\text { Propostas de intervenção } \\
\text { fonoaudiológica no } \\
\text { autismo infantil: revisão } \\
\text { sistemática da literatura }\end{array}$ & Scielo & $\begin{array}{l}\text { Foi realizada pesquisa bibliográfica } \\
\text { utilizando os bancos de dados } \\
\text { eletrônicos Medline, Lilacs e SciELO } \\
(2006-2010) \text {. As palavras-chaves } \\
\text { utilizadas em inglês foram: "autistic } \\
\text { disorder" e "speech therapy" nas bases } \\
\text { de dados Medline e Lilacs e em } \\
\text { português: "autismo" } \\
\text { "fonoaudiologia" na base de dados } \\
\text { SciELO }\end{array}$ & $\begin{array}{l}\text { Por meio do estímulo da comunicação da } \\
\text { criança, na Abordagem Funcional da } \\
\text { Linguagem a criança autista é induzida a se } \\
\text { comunicar oralmente com a intenção de } \\
\text { solicitar algo de seu interesse. Assim, as } \\
\text { atividades são realizadas de forma que a } \\
\text { criança tenha que interagir e se comunicar } \\
\text { com o terapeuta. }\end{array}$ \\
\hline Pastorello, L (2018) & Scielo & $\begin{array}{l}\text { Pesquisa de campo realizada com } \\
\text { crianças autistas em uma clínica }\end{array}$ & $\begin{array}{l}\text { A fonoaudiologia de atuar principalmente com } \\
\text { as questões da linguagem na infância } \\
\text { atendendo crianças e adolescentes com o que } \\
\text { se chama hoje de TEA. Há a necessidade de } \\
\text { recorrer à literatura internacional que ainda é } \\
\text { escassa, sendo o caminho estudar e interpelar }\end{array}$ \\
\hline
\end{tabular}


Research, Society and Development, v. 10, n. 6, e49610615550, 2021

(CC BY 4.0) | ISSN 2525-3409 | DOI: http://dx.doi.org/10.33448/rsd-v10i6.15550

\begin{tabular}{|c|c|c|c|}
\hline & & & $\begin{array}{l}\text { outras áreas do conhecimento como a } \\
\text { psiquiatria, a psicologia, a psicanálise, a } \\
\text { neurologia e os estudos linguísticos. E, } \\
\text { sobretudo publicar. }\end{array}$ \\
\hline Martins, ZL (2013) & Capes & $\begin{array}{l}\text { Participaram desta pesquisa uma } \\
\text { amostra de oito famílias com crianças } \\
\text { com diagnóstico de autismo, } 6 \text { meninos } \\
\text { e } 2 \text { meninas, com idades variável entre } \\
1 \text { ano e } 9 \text { meses e } 3 \text { anos e } 9 \text { meses, } \\
\text { sendo a média de idade igual a } 2 \text { anos e } \\
9 \text { meses de idade. Foram realizadas } \\
\text { uma média de } 24 \text { sessões terapêuticas } \\
\text { no período de agosto a dezembro de } \\
2012 \text {, sendo filmadas uma média de } \\
8 \text { sessõesfonoaudiológicas, com duração } \\
\text { de } 30 \text { minutos, sendo realizadas analise } \\
\text { pragmáticas da primeira e da ultima } \\
\text { sessão de cada uma das crianças. }\end{array}$ & $\begin{array}{l}\text { A intervenção fonoaudiológica colabora para } \\
\text { a evolução e melhora do perfil comunicativo } \\
\text { nas interações entre criança e adulto. Verifica- } \\
\text { se também a importância de considerar não } \\
\text { apenas a quantidade de atos comunicativos na } \\
\text { avaliação da evolução do caso, mas também o } \\
\text { predomínio de funções comunicativas. }\end{array}$ \\
\hline Severo TS (2017) & Capes & $\begin{array}{l}\text { Revisão da literatura utilizando as bases } \\
\text { de dados Pepsic, Psychoinfo, Pubmed, } \\
\text { Scieloe BVS no período de Julho/2016 } \\
\text { a Julho/2017. Como critério de seleção } \\
\text { incluiu-se artigos publicados entre os } \\
\text { anos de } 2002 \text { e } 2017 \text {. No total foram } \\
\text { encontrados } 3.673 \text { artigos. }\end{array}$ & $\begin{array}{l}\text { A fonoterapia pode melhorar a comunicação } \\
\text { geral no autismo, o que possibilita o } \\
\text { desenvolvimento de habilidades sociais e a } \\
\text { autonomia. }\end{array}$ \\
\hline Delfrate CB (2017) & Pubmed & $\begin{array}{l}\text { Analisar longitudinalmente a aquisição } \\
\text { da linguagem de uma criança com } \\
\text { diagnóstico de síndrome autística, a } \\
\text { partir de processos dialógicos e de uma } \\
\text { abordagem discursiva, durante o } \\
\text { período de dois anos e seis meses. }\end{array}$ & $\begin{array}{l}\text { O resultado de tal análise evidenciou que a } \\
\text { criança sujeito desta pesquisa sempre esteve } \\
\text { presente "na língua", e sua ecolalia é a } \\
\text { evidência dessa presença. Seus gestos e sua } \\
\text { fala, considerados em função de situações } \\
\text { interativas estabelecidas com uma } \\
\text { fonoaudióloga, permitiram acompanhar o seu } \\
\text { processo de aquisição de linguagem, bem } \\
\text { como a sua mudança como sujeito da } \\
\text { linguagem, a qual é tomada como atividade } \\
\text { constitutiva do sujeito e da própria linguagem. }\end{array}$ \\
\hline Campelo, LD (2018) & Pubmed & $\begin{array}{l}\text { Foram selecionadas seis crianças com o } \\
\text { diagnóstico de atraso de linguagem } \\
\text { secundário a autismo, submetidas à } \\
\text { terapia fonoaudiológica em uma clínica } \\
\text { escola de uma universidade privada da } \\
\text { cidade do Recife. As crianças foram } \\
\text { observadas em duas sessões de terapia, } \\
\text { que foram gravadas em fita VHS para } \\
\text { posterior análise e discussão. A análise } \\
\text { foi baseada no uso do protocolo de }\end{array}$ & $\begin{array}{l}\text { Em detrimento dos meios vocais e verbais, o } \\
\text { meio gestual apareceu com maior frequência } \\
\text { nos atos comunicativos. Os gestos, mesmo } \\
\text { constituindo uma forma de comunicação não } \\
\text { verbal, demonstraram, muitas vezes, expressar } \\
\text { intenções dos sujeitos. Com relação às } \\
\text { funções comunicativas, pôde-se concluir que } \\
\text { houve uma grande variedade das mesmas, } \\
\text { porém, entre as vinte funções investigadas, } \\
\text { apenas poucas se destacaram. Entre elas, }\end{array}$ \\
\hline
\end{tabular}




\begin{tabular}{|c|c|c|c|}
\hline & & $\begin{array}{l}\text { observação pertencente ao } \mathrm{ABFW} \text {, que } \\
\text { contempla os meios e funções } \\
\text { comunicativas. }\end{array}$ & $\begin{array}{l}\text { apareceram, predominantemente, as funções } \\
\text { não-focalizadas, protesto, exploratória e } \\
\text { reativa. }\end{array}$ \\
\hline Ferreira JTC (2016) & Pubmed & $\begin{array}{l}\text { Tratou-se de um estudo de caso com } \\
\text { cinco crianças com diagnóstico de } \\
\text { autismo. Para avaliação foram } \\
\text { utilizados dois instrumentos: Escala de } \\
\text { Classificação de Autismo na Infância e } \\
\text { Média de Independência Funcional. As } \\
\text { crianças receberam atendimento } \\
\text { fonoaudiológico individual. Cada } \\
\text { sessão durou } 30 \text { minutos, sendo uma } \\
\text { vez por semana, durante } 6 \text { meses. }\end{array}$ & $\begin{array}{l}\text { Concluiu-se, portanto, que a fonoaudiologia } \\
\text { foi eficaz no tratamento deste grupo de } \\
\text { crianças com autismo, principalmente } \\
\text { possibilitando uma maior autonomia. }\end{array}$ \\
\hline
\end{tabular}

Fonte: Autores (2020).

Conforme se evidencia pela presente pesquisa bibliográfica, foram identificados diversos benefícios e contribuições dos profissionais da fonoaudiologia em prol de processos de desenvolvimento de crianças diagnosticas com transtorno do espectro autista.

Dentre os principais benefícios que foram evidenciados, mesmo que após um período de 6 meses, diz respeito ao número de atos comunicativos expressos por minuto, a situação que produziu os melhores resultados foi a de oficina de linguagem. Quanto ao uso dos meios comunicativos, os sujeitos tiveram aumento na proporção do uso do meio verbal e diminuição do uso do meio gestual. Foi possível observar que todos os sujeitos apresentaram aumento na proporção da interatividade da comunicação (Cardoso, 2017).

Outro ponto analisado na pesquisa consiste no maior engajamento de crianças autistas em atividades de atenção compartilhada e jogo simbólico e, aumento significativamente da proporção de comunicação interpessoal (Santos, 2017).

Além de Santos (2017), Souza (2018) também afirma que os sujeitos ampliaram sua participação dialógica em situações de interação verbal, apresentando progressos no funcionamento da linguagem. Desta forma, é possível afirmar a eficácia e efetividade da abordagem na terapêutica de linguagem em sujeitos do espectro autístico, pois permite perceber o avanço no funcionamento da linguagem. Os movimentos terapêuticos consistem em ancorar as enunciações dos sujeitos atribuindo sentido e mantendo o tópico de discurso.

A importância da fonoaudiologia consiste no estímulo da comunicação da criança, na abordagem funcional da linguagem com a criança autista sendo induzida a se comunicar oralmente com a intenção de solicitar algo de seu interesse. Assim, as atividades são realizadas de forma que a criança tenha que interagir e se comunicar com o terapeuta (castro, 2015).

Ainda foi possível evidenciar o fato de os profissionais de fonoaudiologia possuírem a competência de proporcionar aos autistas o desenvolvimento da linguagem mostrando aos pais e responsáveis as principais dificuldades dessas crianças, e assim, os familiares passam a fazer parte da terapia desses indivíduos que necessitam de uma atenção especial.

No entanto o profissional de fonoaudiologia sempre deve estar em conexão direta com outros profissionais, pois para ter efeitos benéficos nas questões da linguagem de crianças autistas, o caminho mais adequado é a interpelação com outras áreas do conhecimento, ressaltando-se principalmente a psiquiatria, a psicologia, a psicanálise, a neurologia e os estudos linguísticos (Pastorello, 2018). 
Por meio da intervenção da fonoaudiologia, com crianças autistas, os fonoaudiólogos colaboram em prol da evolução e da melhora do perfil comunicativo relacionados com as interações entre as crianças diagnosticadas com o transtorno do espectro autista e os adultos. Ainda se pode ratificar que a importância também consiste no fato de considerar não somente o quantitativo dos atos comunicativos durante o processo avaliativo do caso, mas também, deve ser analisado o predomínio de funções comunicativas

Enfim por meio da fonoterapia as crianças com o transtorno do espectro autista podem possuir efeitos muito benéficos no que se refere a comunicação de uma forma geral e consequentemente possibilitando um maior desenvolvimento relacionados com as habilidades sociais e com a autonomia da criança (Severo, 2017).

Por meio do processo referente com a aquisição de linguagem, assim como também com a transformação do autista para um seu jeio ativo da linguagem, passa a construir o seu próprio mundo e consequentemente sem um ser humano com uma maior independência e autonomia (Delfrate, 2017).

No entanto, ainda conforme a presente pesquisa pode se identificar que mesmo com a interação da Fonoaudiologia, há crianças com autismo que tendem a se desenvolver mais em uma área de comunicação não verbal que a comunicação por meio da linguagem, ressaltando mais a forma comunicativa gestual. Ressalta-se que em detrimento dos meios vocais e dos meios verbais, o meio gestual aparece em uma frequência muito maior nos atos comunicativos. Os gestos, mesmo sendo uma forma de comunicação não verbal, demonstraram inúmeras vezes, expressar intenções dos sujeitos. Com relação às funções comunicativas, conclui-se que há uma grande variedade das mesmas, no entanto, entre as várias funções investigadas só poucas se destacaram, ressaltando-se, de forma predominante, as funções não-focalizadas (Camopelo, 2018)

\section{Considerações Finais}

Conforme a presente pesquisa evidenciou-se que por meio da atuação dos fonoaudiólogos, intervindo direta e indiretamente possibilita uma evolução mais ampla no que se refere ao desenvolvimento de crianças com transtornos do espectro autista, principalmente em prol de haver uma maior informação de pais ou responsáveis em prol de um melhor acompanhamento de autistas.

Foi possível constatar que a atuação do fonoaudiólogo por meio da utilização de técnicas pautadas na ludicidade, com os profissionais da fonoaudiologia sendo verdadeiros interlocutores, por meio da utilização de ferramentas com objetos de mediação, são capazes de proporcionar uma intervenção adequada, possibilitando, dessa forma, uma evolução altamente considerável em prol do desenvolvimento da criança autista.

Salienta-se que o profissional da fonoaudiologia por meio da associação dessas técnicas estruturadas e não estruturadas objetivando a priori o desenvolvimento das crianças autistas.

Além disso, é valido destacar que a fonoaudiologia não pode atuar de forma isolada, devendo ser e, ao mesmo tempo possuir o devido suporte de outras áreas de conhecimento, ressaltando-se, principalmente a psiquiatria, a psicologia, a psicanálise, a neurologia e os estudos linguísticos.

Ainda foi identificado por meio da elaboração da presente pesquisa que há uma necessidade de um maior numero de publicações na temática referente aos benefícios da fonoaudiologia no desenvolvimento comunicativo de crianças autistas.

Salienta-se que o principal objetivo da fonoaudiologia no que se refere ao desenvolvimento da criança com transtorno de espectro do autismo (TEA) consiste na melhoria dos sintomas comportamentais, em especial, em aspectos da linguagem e da comunicação, tanto verbal como a comunicação não verbal que por meio da intervenção de forma precoce e contínua dos profissionais da fonoaudiologia é de extrema importância para que o quadro evolua de foram satisfatória, no que envolve a 
comunicação geral e, especialmente, para o desenvolvimento de sua linguagem expressiva e receptiva, linguagem gestual, escrita e oral, capacitando-o para a devida compreensão, a realização das atividades e agir sobre o ambiente no qual o autista está inserido.

\section{Referências}

APA (American Psychiatric Association), 2014. Transtornos mentais. DSM-V. In: APA (American Psychiatric Association), Manual diagnóstico e estatísticos de transtornos mentais. (5a ed.), Artmed,

Araujo, Á. C., \& Lotufo Neto, F (2014). A nova classificação americana para os transtornos mentais: o DSM-5, Rev. bras. ter. comport. cogn. 16(1).

Cardoso, C. (2017) Fonoaudiologia e autismo: resultado de três diferentes modelos de terapia de linguagem. Pró-Fono R. Atual. Cient. 20(4).

Costa, M. A. F. (2015). Projeto de Pesquisa: entenda e faça. (6a ed.), Vozes.

Dannuleo, J. C. (2014). Estudo da produção científica dos docentes de pós-graduação em Fonoaudiologia, no Brasil, para uma análise do domínio. Universidade Estadual Paulista "Júlio de Mesquita Filho" Faculdade de Filosofia e Ciências - Campus Marília Programa de Pós-Graduação em Ciência da Informação. São Paulo,

Delfrate, C. B. (2017). A aquisição de linguagem na criança com autismo: um estudo de caso. Fonoaudiologia em Estudo, 14(2), $321-33$.

Ferreira, J. T. C. (2016). Efeitos da fonoaudiologia em crianças autistas: estudo de séries de casos. Cad. Pós-Grad. Distúrb. Desenvolv. 16(2).

Gil, A. C. (2010) Como elaborar projetos de pesquisa. (5a ed.), Atlas.

Ischkanian, S. H. D. (2014) Letramento e Autismo.

Isaías, J. M. R. Prevalência e Etiologia de Transtornos do Espectro do Autismo:O que mudou nos últimos cinco anos? 2019. 33 f. (Dissertação) -Faculdade de Ciências da Saúde (Universidade de Beira Interior), Covilhã, 2019

Kasari, C. (2016). Assessing Change in Early Intervention Programs for children with Austim. In: Journal of Autism and Developmental Disorders. 54(16).

Lord, C. \& Bishop, S. L. (2014) Recent Advances in Autism Research as Reflected in DSM-5 Criteria for Autism Spectrum Disorder. Annual Review of Clinical Psychology. (11), 53-70.

Manual de orientação. (2019) Transtorno do Espectro do Autismo. Departamento Científico de Pediatria do Desenvolvimento e Comportamento. Sociedade Brasileira de Pediatria. n.5, 24p.

Manual Diagnóstico e Estatístico de Transtornos Mentais (DSMV) (2014) Arlington, VA: American Psychiatric Publishing,

Marcono, M. A., \& Lakatos, E. M. (2017), Metodologia Cientifica. (7a ed.), Atlas.

Minayo, M. C. (2010). O desafio do conhecimento. Hucitec.

Oiliveira, T. R. S., et al (2018). Intervenção fonoaudiólogica e autismo. Rev. CEFAC. 20(6), 808-814

Oliveira, et al. (2017) Atividade física e promoção da saúde na escola: coletânea de estudos [recurso eletrônico] / Organizadores, Antonio Ricardo Catunda de Oliveira. [et al]. EdUECE,

Pastorello, L. (2018). Autismo e Fonoaudiologia. http://www.fonosp.org.br/noticias/1387-artigo-autismo-e-fonoaudiologia.

Reis, L. G (2012). Da teoria à prática o método educar pela pesquisa (MEP). (4a ed.), Revisada e ampliada. Senac-DF.

Severo, T. S. (2017). de. Transtorno do Espectro Autista nas abordagens Psicodinâmica e Cognitivo Comportamental: Uma revisão narrativa da literatura.30f. 2017. Trabalho de Conclusãode Curso (Graduação em Psicologia) Universidade Federal de Pelotas, 2017

Silva, E. L., \& Menezes, E. M. (2005). Metodologia da pesquisa e elaboração de dissertação. (4a ed.), UFSC. 138 p.

Teixeira, G. (2016). Manual do Autismo. Best Seller. 